\title{
Epidemiology of traumatic spinal cord injury in Norway in 2012- 2016: a registry-based cross-sectional study
}

\author{
A. Halvorsen ${ }^{1,2} \cdot$ A. L. Pettersen ${ }^{1} \cdot$ S. M. Nilsen ${ }^{1,3} \cdot$ K. Krizak Halle ${ }^{1} \cdot$ E. Elmenhorst Schaanning ${ }^{4} \cdot$ T. Rekand $^{5,6}$
}

Received: 10 August 2018 / Revised: 6 November 2018 / Accepted: 7 November 2018 / Published online: 20 December 2018

(c) International Spinal Cord Society 2018

\begin{abstract}
Study design A registry-based cross-sectional study.

Objectives To analyse the epidemiological and demographic characteristics of persons with traumatic spinal cord injury (TSCI) in Norway.

Setting TSCI patients admitted for primary rehabilitation to one of the three specialised spinal cord injury (SCI) departments (located in Bergen, Trondheim, and Oslo) and consented to the Norwegian Spinal Cord Injury Registry (NorSCIR).

Methods Analysis of data from NorSCIR during a 5-year period (2012-2016) was performed. Data were collected by using the International SCI Core Data Set as recommended by the International Spinal Cord Society (ISCoS).

Results The lowest incidence of TSCI was 11.4/million (2012), and the highest incidence was 15.9/million (2014). In the study period, 349 individuals were registered with TSCI. In total, $76 \%$ were male, and the mean age was 47 (SD \pm 19 ) years. We observed dominance in the 60-74 years age group. The distribution between tetraplegia and paraplegia was $48 \% / 42 \%$. For those initially classified as American Spinal Cord Injury Association Impairment Scale (AIS) grade A (complete injury), $77 \%$ remained grade $\mathrm{A}$ at discharge. Considerable changes during primary rehabilitation after incomplete lesions were observed. Most patients (68\%) were discharged home after primary rehabilitation. Falls were the main cause of TSCI (47\%) and occurred more often during the weekend.

Conclusion Through a National Medical Quality Registry based on internationally provided data sets, we are able to present systematic and updated data from Norway.
\end{abstract}

\section{Introduction}

Norway has succeeded in creating large, important and longitudinal population-based databases and biobanks. Together with national health registries and the personal identification number, these databases offer unique possibilities to perform excellent research from a national perspective [1]. Medical quality registers are typically based on pre-defined sets of criteria for specific medical conditions or procedures. Their purpose is to improve quality of care, to establish and monitor clinical guidelines and to serve as a resource for research by providing comprehensive data on the patient group of interest.

The Norwegian Spinal Cord Injury Registry (NorSCIR) was established in 2009 by the three specialised SCI

\section{A. Halvorsen}

annette.halvorsen@stolav.no

Extended author information available on the last page of the article. departments in Norway in cooperation with the National Spinal Cord Injuries Association (LARS). NorSCIR has been in operation since 2011 and was authorised by the Ministry of Health and Care Services as a national quality registry in 2012 .

Norway has a public health system that includes all citizens with a permanent address in the country, providing health care for everyone independent of insurance. Traumatic SCI patients are initially transported to one of the specialised trauma hospitals located in the cities of Oslo, Bergen, Trondheim, Stavanger, and Troms $\varnothing$. After acute treatment, the patients are transferred to one of the three specialised SCI centres for rehabilitation.

The ministry of Social and Health Services decided in 1995 to centralise the rehabilitation and follow-up of spinal cord injury (SCI) patients in Norway to three specialised centres, located at Haukeland University Hospital, St. Olav's University Hospital, and Sunnaas Rehabilitation Hospital. A description of the Norwegian SCI care, 
including the patients' journey through the chain of care, was previously published [2].

Previous epidemiological SCI studies in Norway are geographically limited and no longer current [3-5]. An older survey based on interviews at all Norwegian hospitals in 1974-1975 estimated a TSCI incidence of 16.5 per million inhabitants per year [4]. Another study based on a population in western Norway during the period of 1952-2001 reported an increased TSCI incidence from 5.9 per million in the first decade to 21.2 per million in the last [5].

Our objective in this study is to utilise and analyse the best available standardised data to provide an up-to-date, epidemiological status on TSCI in Norway. Using this registrybased cross-sectional study, we aim to determine the incidence of traumatic SCI and to describe TSCI characteristics.

\section{Methods}

\section{Setting and population}

The Norwegian population was 4.99 million on 1.1.2012 and 5.26 million on 31.12.2016 [6].

All traumatic and non-traumatic patients who were admitted to one of the three specialised SCI departments for primary rehabilitation of a spinal cord or cauda equina injury and consented to registration in NorSCIR during the study period of 1.1.2012-31.12.2016 were included. Material regarding non-traumatic SCI is excluded and published seperate [7]. Registration in the registry is voluntary, and written informed consent is obtained before registration occurs. Annual analyses reveals $>90 \%$ coverage during the entire period [8]. To calculate the coverage ratio, the number of patients in the registry is compared with the patient data from electronic medical records.

\section{Study design}

A registry-based cross-sectional study of incidence, clinical findings, and outcomes for patients, with a new TSCI admitted to one of the three specialised SCI departments in Norway during the study period, was performed. Traumatic spinal cord injury (TSCI) is defined as impairment of the spinal cord or cauda equina function resulting from the application of an external force of any magnitude [9].

\section{Study variables}

The current study from NorSCIR used the International SCI Core Data Set (version 1.1) as recommended by the International Spinal Cord Society (ISCoS), which includes birth date, injury date, acute admission, final inpatient discharge, total days hospitalised, gender, injury aetiology, vertebral injury, associated injury, spinal surgery, ventilatory assistance, place of discharge, and neurological data [10].

The International Standards for Neurological Classification of SCI (ISNCSCI) includes the clinical findings standardised by the American Spinal Injury Association (ASIA) Impairment Scale (AIS) [11-13].

\section{Data collection and analysis}

NorSCIR is based on the international SCI Data Sets developed by ISCoS [14]. The registration is electronic and runs on the Medical Registry System (MRS) developed by the Central Norway Regional Health Authority IT department (Hemit). Data are transferred via the Norwegian Health Network.

Data collection was conducted during the primary stay at the specialised SCI department during the study period. The neurological level of injury and the degree of impairment after injury were assessed by a medical doctor specialised in SCI, most often together with a physiotherapist. In most cases, the examination was performed during the first week after admission and during the last week before discharge from the specialised SCI departments.

The analyses follow the recommendations from the International Spinal Cord Injury Core Data Set [15]; continuous variables are expressed as both mean with standard deviation and median with range. Categorical variables are presented as number of cases and percentages. The categorisation of age groups was performed according to the newest recommendations [9]. Participants' demographics and injury characteristics are analysed descriptively.

Population data from Statistics Norway [6] were obtained to calculate the annual incidence rates of SCI patients admitted for primary rehabilitation per million inhabitants stratified by age and gender. The WHO standard population was used to calculate the age-standardised incidence rates [16]. The incidence rates were adjusted for age by direct standardisation.

IBM SPSS Statistics version 23 and Microsoft Excel 2010 were used to perform all of the statistical analyses.

\section{Results}

In the period of 2012-2016, 349 individuals with a recent traumatic SCI or cauda equina were hospitalized for rehabilitation at a specialised SCI department and consented to NorSCIR. In 2015, one person suffered two spinal cord injuries on two different occasions.

\section{Number of cases, incidence, injuries per weekday, and seasonal variation of $\mathrm{TSCl}$}

The number of cases, incidence, injuries per weekday, and seasonal variation are described in Table 1 , Table 2, and 
Fig. 1. Seasonal variation in TSCI incidence reveals variation from year to year. However, TSCIs occurred more often during the spring and summer months. The peak days for occurrence of TSCI were Saturday and Sunday, and $41 \%$ of all TSCI occurred during weekends. Falls were the main cause throughout all weekdays and are the cause of injury that drives the increased occurrence during weekends.

\section{Epidemiological characteristics of TSCI}

An overview of demographic and clinical characteristics of the TSCI patients is presented in Table 3. In the study period, 349 patients were registered with TSCI. In total, $76 \%$ were male, and the mean age was 47 years (SD 19). The youngest patient was 11 months, and the oldest was 85 years.

Approximately half of traumatic SCI injuries were caused by falling, followed by sports (21\%) and transport $(18 \%)$. The average total length of stay from admission to the acute hospital to discharge from the primary rehabilitation at the specialized SCI department was 120 days, with a median of 108 days (min 11 days, $\max 313$ days). The length of stay in our study was defined as the total number of acute days and rehabilitation days minus "out of hospital" days.

Associated severe injuries as defined by ISCoS were present in $23 \%(N=81)$. Spinal surgical procedures were performed in 311 of 349 cases (89\%) during the inpatient hospitalisation following SCI. The place of discharge was most often home $(68 \%)$, and only $8 \%$ of patients were

Table 1 TSCI incidence based on data from NorSCIR 2012-2016 $(N=349)$, incidence rates per million inhabitants

\begin{tabular}{llllll}
\hline & 2012 & 2013 & 2014 & 2015 & 2016 \\
\hline Number of cases per year & 57 & 60 & 81 & 76 & 75 \\
Incidence per year & 11.4 & 11.9 & 15.9 & 14.7 & 14.4 \\
Age-standardised incidence & 9.1 & 9.4 & 13.4 & 14.0 & 12.4 \\
$\begin{array}{l}\text { Incidence by gender } \\
\text { Male }\end{array}$ & 17.6 & 18.9 & 23.4 & 22.7 & 20.6 \\
Female & 5.2 & 4.8 & 8.3 & 6.6 & 8.1 \\
Incidence by age & & & & & \\
0-14 & 0 & 0 & 3.2 & 0 & 4.3 \\
15-29 & 10.2 & 9.0 & 14.8 & 26.4 & 16.5 \\
30-44 & 13.3 & 12.3 & 17.0 & 13.2 & 8.5 \\
$45-59$ & 10.2 & 15.1 & 15.9 & 17.6 & 14.5 \\
$60-74$ & 27.1 & 26.3 & 35.0 & 18.4 & 32.0 \\
$75+$ & 11.4 & 11.4 & 8.5 & 8.3 & 13.7 \\
\hline
\end{tabular}

${ }^{\mathrm{a}}$ This table presents results based on data from NorSCIR. All cases may not be included due to NorSCIR inclusion criteria. For example, children admitted to paediatric departments or individuals who do not consent to NorSCIR are not included discharged to a nursing home. The mean age of persons discharged to a nursing home was 62 years (median 68, minimum 24 , and maximum 85 ). A minority (15 persons) used different methods of ventilatory assistance to sustain respiration on the date of final inpatient discharge.

The distribution between tetraplegia and paraplegia was $48 \% / 42 \%$, and in $10 \%$ of the cases, the classification was not performed, was unknown or was not applicable (Table 3). Among individuals with tetraplegia, 63\% had a high cervical neurological lesion (C1-C4). In addition, $67 \%$ of the individuals with paraplegia had a thoracic lesion.

Regarding the extent of injury, most individuals were classified at admission with a motor incomplete lesion, including $43 \%$ with AIS grade D and $15 \%$ with AIS C.

In total, $23 \%$ of cases were classified at admission at the SCI department as motor and sensory complete lesions (AIS grade A), and only $10 \%$ were classified with a sensory incomplete lesion (AIS grade B).

In $9 \%$ of the individuals, the classification was not performed, was unknown or was not applicable. In total, 263 participants had two AIS grades performed at admission and discharge from the SCI department, separately. For those initially classified as AIS grade A, 77\% remained AIS grade $\mathrm{A}$ at discharge. More substantial changes during primary rehabilitation were noted for those with incomplete lesions (Table 4).

\section{Patient age and gender and aetiology of injury characteristics}

Fall was the cause of injury for $65 \%$ of the patients older than 60 years, whereas $38 \%$ of the injuries were caused by sports, $28 \%$ by falls and $27 \%$ by transport for patients between 15 and 29 years. Of the seven children, three had other traumatic causes (Fig. 2).

Approximately one-third of the patients injured by transport and sports were graded with a complete injury (AIS grade A) at admission to the SCI department (Fig. 3). The male-to-female ratio was highest among the patients with transport as a cause for injury (14/1) and in the 30-44 years age group (6/1). Females comprised the majority $(0.25 / 1)$ in the group injured by assault, but this was fortunately a small group.

\section{Discussion}

This is the first registry-based study on the national incidence for TSCI in Norway. The strength of this study is the national approach using the Norwegian SCI quality registry, which includes data from a 5-year period. We are able to provide a prospective collection of standardised data with 
Table 2 Seasonal variation of injury, number of TSCI cases per month ${ }^{\mathrm{a}}(N=349)$

\begin{tabular}{llllllllllllll}
\hline & Jan & Feb & Mar & Apr & May & Jun & Jul & Aug & Sep & Oct & Nov & Dec & Total \\
\hline 2012 & 6 & 2 & 2 & 6 & 7 & 3 & 5 & 13 & 1 & 5 & 3 & 4 & 57 \\
2013 & 2 & 4 & 3 & 4 & 5 & 6 & 10 & 6 & 3 & 5 & 5 & 7 & 60 \\
2014 & 6 & 6 & 6 & 8 & 10 & 6 & 6 & 10 & 8 & 3 & 6 & 6 & 81 \\
2015 & 4 & 5 & 7 & 8 & 6 & 13 & 8 & 6 & 1 & 6 & 7 & 5 & 76 \\
2016 & 13 & 2 & 7 & 8 & 7 & 10 & 5 & 4 & 5 & 5 & 5 & 4 & 75 \\
Total & 31 & 19 & 25 & 34 & 35 & 38 & 34 & 39 & 18 & 24 & 26 & 26 & 349 \\
\hline
\end{tabular}

${ }^{\mathrm{a}}$ Based on date of admission to acute hospital

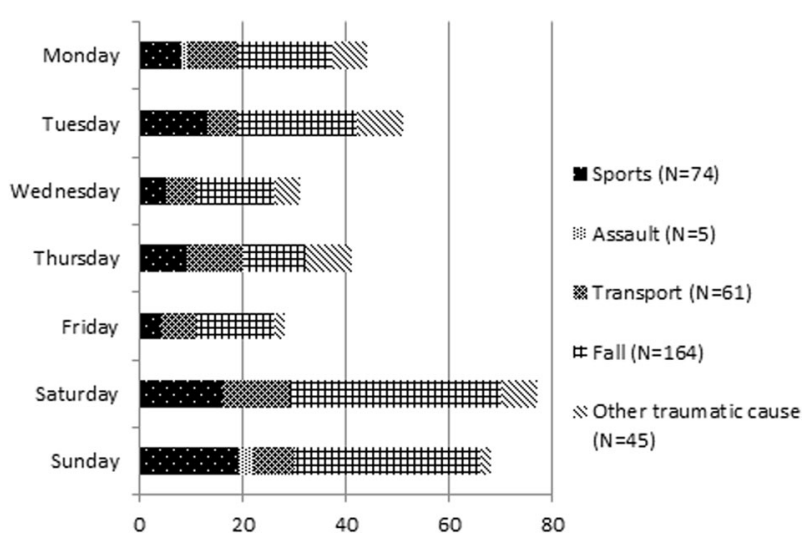

Fig. 1 Weekday variation in injury, number of TSCI cases per weekday $(N=340)^{*}$. Injuries by day of the week in traumatic spinal cord injury (TSCI) in Norway for the period 2012-2016. The peak days for occurrence of TSCI were Saturday and Sunday, and $41 \%$ of all TSCI occurred during weekends. *The "injury date" is missing for 9 subjects, and these subjects are excluded from the figure

insight into TSCI characteristics and neurological classification of SCI at admission and discharge from rehabilitation. The centralised SCI care in Norway contributes to highly experienced SCI professionals performing consistent clinical evaluations and collecting data. Data quality is high given the monitoring activity and continuous communication between the steering committee of NorSCIR and all three hospitals.

The incidence based on data from NorSCIR is less than that previously reported in a study in western Norway that measured a TSCI incidence of 26.3 per million inhabitants in 1997-2001 [5]. The lower incidence in our study may be explained by changes in risk factors, increased awareness about TSCI, consent requirements and more systematic data collection compared with previous studies. Studies from other Nordic countries revealed a variety of incidence rates ranging from 9.2/million in Denmark to 38.1/million in Finland $[5,17-20]$. The incidence seems to vary in Scandinavia, but the results might also depend on the research tools used. Therefore, systematic studies using similar international standards may yield more comparable results. The incidence of TSCI in our study was comparable to the TSCI incidence in other SCI registry-based studies in other western European countries [21, 22]. The global incident rate was estimated to be 23 TSCI cases per million inhabitants per year [23].

We observed a trend that TSCIs occurred more often during the spring and summer months and during the weekend. This finding may be explained by leisure activities among Norwegians that have potential to cause TSCI. Of note, alcohol and drug use were previously identified as contributing factors to TSCI in several studies [24, 25]. Unfortunately, the Norwegian SCI registry did not collect information about alcohol consumption or drug use prior to injury.

We observed most persons with a TSCI in the 60-74 years age group. Young populations were previously thought to be most prone to traumatic SCI. However, variations in age at the time of injury have been reported worldwide in previous epidemiological studies. The average age at the time of injury has been reported to be from 26.8 years in Turkey to 55.5 years in the USA [26]. During the 5 years our study covered, only 19 persons older than 75 years were registered. We are unsure of whether this finding is due to a lower incidence of TSCI in this age group given a more retracted lifestyle or if there are other explanations. The steady increase in the mean age for TSCI during the past five decades in the last century seems to have stabilised [5].

The male-to-female ratio was 3:1. This finding is consistent with results from a systematic review in 2014 that revealed a greater percentage of males with SCI than females in all countries [27]. The male-to-female ratio varies in the aetiology groups. The highest ratio (14:1) was reported for transport. A previous study demonstrated that men exhibit more risk-taking behaviour than woman [28].

The leading cause of TSCI was falls, followed by sports and transport. The frequency of falls was similar to that reported in a previous study in western Norway and more recent studies in Europe [29, 30]. Norway has fewer patients injured by transport than other countries. On a global level, traffic accidents involving motor vehicles, bicycles, or pedestrians account for the greatest number of SCIs (typically $50 \%$ of all injuries) [31]. It is challenging to compare differences in SCI causation among countries due to the use of different definitions in studies. Because it is possible that an injury event may be classifiable into more than one category, a protocol for prioritising the assigning 
Table 3 Epidemiological characteristics TSCI

\begin{tabular}{|c|c|c|c|c|c|c|c|c|c|c|c|c|}
\hline \multirow{4}{*}{$\begin{array}{l}\text { Number of cases TSCI } \\
\text { Mean age (SD) }\end{array}$} & \multirow{2}{*}{\multicolumn{2}{|c|}{$\frac{2012}{57}$}} & \multirow{2}{*}{\multicolumn{2}{|c|}{$\frac{2013}{60}$}} & \multirow{2}{*}{\multicolumn{2}{|c|}{$\frac{2014}{81}$}} & \multirow{2}{*}{\multicolumn{2}{|c|}{$\frac{2015}{76}$}} & \multirow{2}{*}{\multicolumn{2}{|c|}{$\frac{2016}{75}$}} & \multicolumn{2}{|c|}{ Total } \\
\hline & & & & & & & & & & & & \\
\hline & \multicolumn{2}{|c|}{49 (19) } & \multicolumn{2}{|c|}{$51(18)$} & \multicolumn{2}{|c|}{$48(20)$} & \multicolumn{2}{|c|}{$43(18)$} & \multicolumn{2}{|c|}{$47(21)$} & \multicolumn{2}{|c|}{47 (19) } \\
\hline & $N$ & $\%$ & $N$ & $\%$ & $N$ & $\%$ & $N$ & $\%$ & $N$ & $\%$ & $N$ & $\%$ \\
\hline \multicolumn{13}{|l|}{ Age } \\
\hline $0-14$ & 0 & $(0.0)$ & 0 & $(0.0)$ & 3 & (3.7) & 0 & $(0.0)$ & 4 & (5.3) & 7 & (2.0) \\
\hline $15-29$ & 10 & (17.5) & 9 & $(15.0)$ & 15 & (18.5) & 27 & $(35.5)$ & 17 & (22.7) & 78 & $(22.3)$ \\
\hline $30-44$ & 14 & $(24.6)$ & 13 & $(21.7)$ & 18 & $(22.2)$ & 14 & (18.4) & 9 & $(12.0)$ & 68 & (19.5) \\
\hline $45-59$ & 10 & $(17.5)$ & 15 & $(25.0)$ & 16 & (19.8) & 18 & (23.7) & 15 & $(20.0)$ & 74 & $(21.2)$ \\
\hline $60-74$ & 19 & (33.3) & 19 & (31.7) & 26 & $(32.1)$ & 14 & (18.4) & 25 & (33.3) & 103 & $(29.5)$ \\
\hline $75+$ & 4 & (7.0) & 4 & (6.7) & 3 & (3.7) & 3 & (3.9) & 5 & (6.7) & 19 & (5.4) \\
\hline \multicolumn{13}{|l|}{ Gender } \\
\hline Male & 44 & $(77.2)$ & 48 & $(80.0)$ & 60 & (74.1) & 59 & (77.6) & 54 & $(72.0)$ & 265 & $(75.9)$ \\
\hline Female & 13 & $(22.8)$ & 12 & $(20.0)$ & 21 & (25.9) & 17 & (22.4) & 21 & $(28.0)$ & 84 & $(24.1)$ \\
\hline \multicolumn{13}{|l|}{ Cause of injury } \\
\hline Sports & 9 & (15.8) & 16 & (26.7) & 18 & $(22.2)$ & 16 & $(21.1)$ & 15 & (20.0) & 74 & $(21.2)$ \\
\hline Assault & 1 & $(1.8)$ & 0 & $(0.0)$ & 1 & $(1.2)$ & 2 & $(2.6)$ & 1 & (1.3) & 5 & (1.4) \\
\hline Transport & 7 & (12.3) & 10 & $(16.7)$ & 16 & (19.8) & 15 & (19.7) & 13 & $(17.3)$ & 61 & $(17.5)$ \\
\hline Fall & 32 & $(56.1)$ & 28 & $(47.7)$ & 36 & (44.4) & 35 & $(46.1)$ & 33 & $(44.0)$ & 164 & $(47.0)$ \\
\hline Other traumatic cause & 8 & $(14.0)$ & 6 & $(10.0)$ & 10 & $(12.3)$ & 8 & $(10.5)$ & 13 & $(17.3)$ & 45 & $(12.9)$ \\
\hline Unspecified or unknown & 0 & $(0.0)$ & 0 & $(0.0)$ & 0 & $(0.0)$ & 0 & $(0.0)$ & 0 & $(0.0)$ & 0 & $(0.0)$ \\
\hline \multicolumn{13}{|c|}{ Level of injury and AIS at admission } \\
\hline C1-C4 AIS A, B, C & 6 & $(10.5)$ & 11 & $(18.3)$ & 19 & $(23.5)$ & 10 & $(13.2)$ & 15 & $(20.0)$ & 61 & $(17.5)$ \\
\hline C5-C8 AIS A, B, C & 3 & (5.3) & 5 & $(8.3)$ & 3 & (3.7) & 5 & $(6.6)$ & 3 & $(4.0)$ & 19 & (5.4) \\
\hline Paraplegia AIS A, B, C & 13 & $(22.8)$ & 10 & $(16.7)$ & 20 & $(24.7)$ & 24 & $(31.6)$ & 19 & $(25.3)$ & 86 & $(24.6)$ \\
\hline All AIS D & 26 & $(45.6)$ & 25 & $(41.7)$ & 33 & $(40.7)$ & 31 & $(40.8)$ & 35 & $(46.7)$ & 150 & $(43.0)$ \\
\hline All AIS E & 1 & $(1.8)$ & 1 & $(1.7)$ & 0 & $(0.0)$ & 0 & $(0.0)$ & 0 & $(0.0)$ & 2 & $(0.6)$ \\
\hline Unknown or not applicable & 8 & $(14.0)$ & 8 & $(13.3)$ & 6 & (7.4) & 6 & (7.9) & 3 & $(4.0)$ & 31 & $(8.9)$ \\
\hline \multicolumn{13}{|l|}{ Neurological level of injury } \\
\hline Tetraplegia & 22 & $(38.6)$ & 34 & $(56.7)$ & 39 & $(48.1)$ & 35 & $(46.1)$ & 39 & $(52.0)$ & 169 & $(48.4)$ \\
\hline Paraplegia & 27 & $(47.4)$ & 17 & $(28.3)$ & 33 & $(40.7)$ & 35 & $(46.1)$ & 34 & $(45.3)$ & 146 & $(41.8)$ \\
\hline Unknown or not applicable & 8 & $(14.0)$ & 9 & $(15.0)$ & 9 & $(11.1)$ & 6 & (7.9) & 2 & $(2.7)$ & 34 & $(9.7)$ \\
\hline \multicolumn{13}{|l|}{ Discharge location } \\
\hline Home & 42 & $(73.7)$ & 42 & $(70.0)$ & 52 & $(64.2)$ & 51 & $(67.1)$ & 51 & $(68.0)$ & 238 & $(68.2)$ \\
\hline Other & 15 & (26.3) & 18 & $(30.0)$ & 29 & $(35.8)$ & 25 & (32.9) & 24 & (32.0) & 111 & (31.8) \\
\hline
\end{tabular}

AIS American Spinal Injury Association Impairment Scale, AIS A motor-sensory complete, AIS B motor complete-sensory incomplete, AIS C-D motor-sensory incomplete, AIS E normal examination, TSCI traumatic spinal cord injury of codes has been established. Third priority for traumatic SCI is given to transport according to the international SCI Core Data Set. This criterion may cause differences in estimations.

Falls are particularly associated with incomplete lesions (76\%), and this finding is consistent with a previous study [5]. One-third of the patients injured by transport and sports were graded with a complete injury $(33 \%)$. Regarding the level of injury, $77 \%$ of the patients initially diagnosed as AIS A (complete injury) did not convert, and this finding is also consistent with other studies [32].
More persons with tetraplegia than with paraplegia were observed in this study. Different geographical predominance of tetraplegia and paraplegia is reported in Europe [33].

The place of discharge was most often a private residence. Discharge to home is probably expected and the most desirable outcome for persons with SCI, although conditions at home usually must be adjusted. In our study, only $8 \%$ of patients with TSCI were discharged to a nursing home. Sixty patients with TSCI received another form of rehabilitation at discharge before entering their home. 
Table 4 Changes in AIS grades during primary rehabilitation for TSCI from admission to discharge from the SCI department

\begin{tabular}{|c|c|c|c|c|c|c|c|c|c|c|c|c|c|}
\hline \multirow[b]{3}{*}{ AIS at admission } & \multirow[b]{3}{*}{ Total } & \multicolumn{12}{|c|}{ AIS at discharge } \\
\hline & & A & Complete & $\mathrm{B}$ & Incomplete & $\mathrm{C}$ & Incomplete & $\mathrm{D}$ & Incomplete & $\mathrm{E}$ & Normal & $\mathrm{U}$ & $\begin{array}{l}\text { Unknown or } \\
\text { not applicable }\end{array}$ \\
\hline & & $N$ & $\%$ & $N$ & $\%$ & $N$ & $\%$ & $N$ & $\%$ & $N$ & $\%$ & $N$ & $\%$ \\
\hline A Complete injury & 79 & 61 & 77 & 2 & 3 & 4 & 5 & 2 & 3 & 0 & 0 & 10 & 13 \\
\hline B Incomplete injury & 35 & 1 & 3 & 14 & 40 & 12 & 34 & 3 & 9 & 0 & 0 & 5 & 14 \\
\hline C Incomplete injury & 52 & 0 & 0 & 0 & 0 & 14 & 27 & 30 & 58 & 0 & 0 & 8 & 15 \\
\hline D Incomplete injury & 150 & 0 & 0 & 0 & 0 & 1 & 1 & 114 & 76 & 4 & 3 & 31 & 21 \\
\hline E Normal & 2 & 0 & 0 & 0 & 0 & 0 & 0 & 0 & 0 & 1 & 50 & 1 & 50 \\
\hline $\begin{array}{l}\text { U Unknown or } \\
\text { not applicable }\end{array}$ & 31 & 2 & 6 & 2 & 6 & 0 & 0 & 13 & 42 & 1 & 3 & 13 & 42 \\
\hline Total & 349 & 64 & 18 & 18 & 5 & 31 & 9 & 162 & 46 & 6 & 2 & 68 & 19 \\
\hline
\end{tabular}

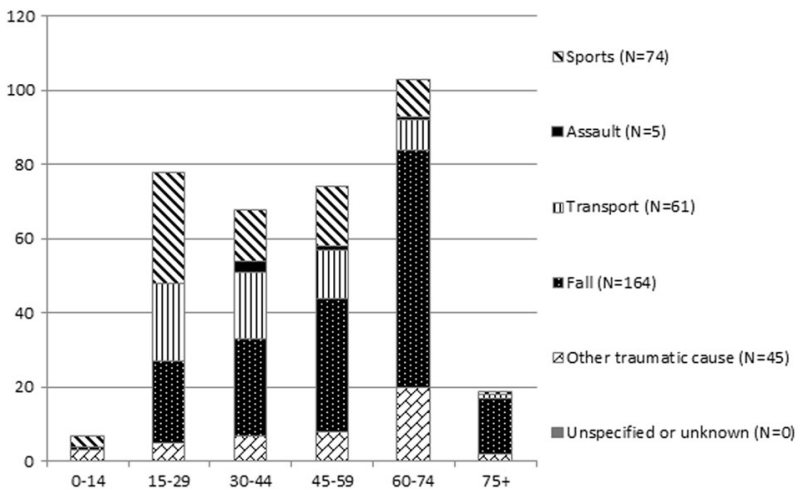

Fig. 2 Causes of TSCI per age group. The leading cause of TSCI was falls. In the age group 15-29 most injuries were caused by sports

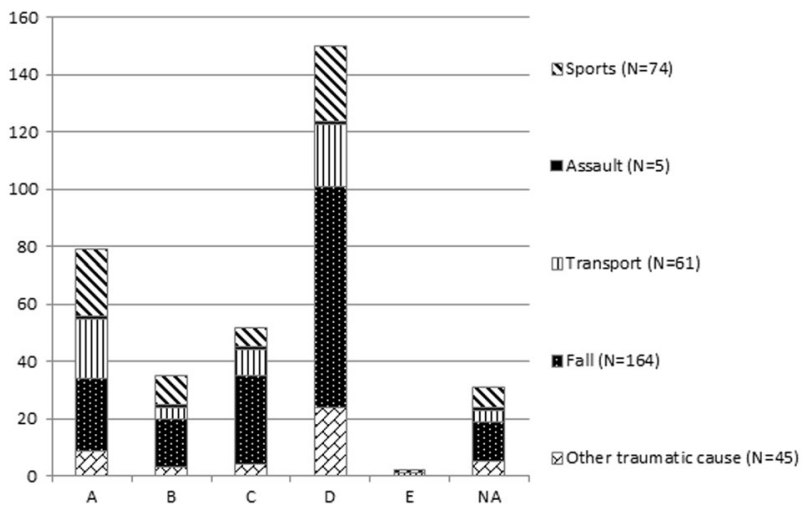

Fig. 3 Causes of TSCI and AIS grade at admission to the SCI department. Incomplete lesions were dominant, and particularly falls were associated with incomplete lesions. NA, the classification was not performed, was unknown or was not apllicable

\section{Data archiving}

The data used in this study are from the NorSCIR. There are restrictions on the use of data from a national medical quality registry. These data were used under licence for the current study, and are not publicly available. Some of the used data are available from the corresponding author on reasonable request.

\section{Limitations}

Written informed consent was obtained from participants before data were entered into the registry. We are not allowed to collect information about patients without consent.

90\% of admitted patients consented to NorSCIR, causing a potential underestimation of the incidence.

Patients with limited findings or quick recovery may be admitted to other departments or discharged home. It may be possible that elderly people with TSCI are less often transferred to a specialized SCI department, for example, given the limited possibility for rehabilitation due to comorbidities.

Persons with TSCI who die in the acute phase are not included in this study. A previous study demonstrated that when individuals with TSCI who die at the scene of the accident are included, the incidence may be increased [34].

Unfortunately, the Norwegian SCI registry contains no information about alcohol consumption or drug use prior to injury given that this information is not included in the data set.

\section{Main conclusion and an indication of the direction for future research}

The collection of data on SCI patients by using the ISCoS core data set allows us for the first time to estimate the incidence of TSCI in Norway. National registries provide data essential for identifying incident trends. Our data reveal a low incidence of TSCI in Norway compared with globally estimated data. We observed that TSCIs occurred 
more often during the spring and summer months and during the weekend. Further research may reveal a relation between activities during leisure time and other known risk factors, such as alcohol consumption prior to traumatic SCI.

Another direction for future research may be to assess SCI rehabilitation related to age. It is important to focus on incidence rates related to different age groups and further on the needs for specialized rehabilitation among elderly individuals.

Acknowledgements We acknowledge the three SCI specialized centres, located at Haukeland University Hospital, St. Olav's University Hospital and Sunnaas Rehabilitation Hospital for registration in the Norwegian SCI registry. We would like to thank all members of the Norwegian SCI registry steering committee for support and data collection, and the National Spinal Cord Injuries Association for good cooperation and enthusiasm.

Funding This study was financed by St. Olavs hospital, Trondheim University Hospital, Norway. SMN was funded by the Norwegian research council (Grant number 256579).

Author contributions AH, ALP, and TR analysed and interpreted the data, prepared and revised manuscript content. SMN in collaboration with KKH provided statistical guidance/support and critically revised the manuscript content. AH, ALP, TR, EES also critically revised manuscript content and supported data collection. All authors have given their final approval of the version to be submitted.

\section{Compliance with ethical standards}

Ethical-legal aspects The NorSCIR registry is approved by the Norwegian Data Protection Authority (09/01084-2/CGN). Registration in the registry is voluntary, and written informed consent is obtained before registration occurs. Ethical approval for this study was obtained from regional committees for medical and health research ethics (2017/1092).

Conflict of interest The authors declare that they have no conflict of interests.

\section{References}

1. Evaluation of biology, medicine and health research in Norway. Oslo: The Research Council of Norway; 2011. ISBN 978-82-1203002-2 (pdf)

2. Strom V, Manum G, Leiulfsrud A, Wedege P, Rekand T, Halvorsen A, et al. People with spinal cord injury in Norway. Am J Phys Med Rehabil. 2017;96:S99-101.

3. Lidal IB, Snekkevik H, Aamodt G, Hjeltnes N, Biering-Sorensen F, Stanghelle JK. Mortality after spinal cord injury in Norway. J Rehabil Med. 2007;39:145-51.

4. Gjone R, Nordlie L. Incidence of traumatic paraplegia and tetraplegia in Norway: a statistical survey of the years 1974 and 1975. Paraplegia. 1978;16:88-93.

5. Hagen EM, Eide GE, Rekand T, Gilhus NE, Gronning M. A 50year follow-up of the incidence of traumatic spinal cord injuries in Western Norway. Spinal Cord. 2010;48:313-8.
6. Statistics Norway. Folkemengde per 1. januar, fødte, døde, flyttinger og folketilvekst (SA 48). Oslo: Statistics Norway; 2018. https://www.ssb.no/300132/folkemengde-per-1.januar-fodtedode-flyttinger-og-folketilvekst-sa-48.

7. AH et al. Non-traumatic spinal cord injury in Norway 2012-2016: Analysis from a national registry and comparison with traumatic spinal cord injury. Spinal Cord 2018.

8. Halvorsen A, Pettersen AL. Norwegian SCI registry Trondheim: St Olavs Hospital; 2018. https://stolav.no/fag-og-forskning/ medisinske-kvalitetsregistre/norsk-ryggmargsskaderegisternorscir\#rapporter.

9. Biering-Sorensen F, DeVivo MJ, Charlifue S, Chen Y, New PW, Noonan V, et al. International Spinal Cord Injury Core Data Set (version 2.0)-including standardization of reporting. Spinal Cord. 2017;55:759-64.

10. DeVivo M, Biering-Sorensen F, Charlifue S, Noonan V, Post M, Stripling $\mathrm{T}$. et al. International spinal cord injury core data set. Spinal Cord. 2006;44:535-40.

11. Marino RJ, Barros T, Biering-Sorensen F, Burns SP, Donovan WH, Graves DE, et al. International standards for neurological classification of spinal cord injury. J Spinal Cord Med. 2003;26: S50-6.

12. Waring WP 3rd, Biering-Sorensen F, Burns S, Donovan W, Graves D, Jha A, et al. 2009 review and revisions of the international standards for the neurological classification of spinal cord injury. J Spinal Cord Med. 2010;33:346-52.

13. Kirshblum SC, Burns SP, Biering-Sorensen F, Donovan W, Graves DE, Jha A, et al. International standards for neurological classification of spinal cord injury (revised 2011). J Spinal Cord Med. 2011;34:535-46.

14. Biering-Sorensen F, Charlifue S, DeVivo M, Noonan V, Post M, Stripling T, et al. International spinal cord injury data sets. Spinal Cord. 2006;44:530-4.

15. DeVivo MJ, Biering-Sorensen F, New P, Chen Y. Standardization of data analysis and reporting of results from the International Spinal Cord Injury Core Data Set. Spinal Cord. 2011;49:596-9.

16. Ahmad OB, Boschi-Pinto C, Lopez AD, Murray CJL, Lozano R, Inoue M. Age standardization of rates: a new who standard. GPE Discussion Paper Series: No. 31. World Health Organization; 2001. https://www.who.int/healthinfo/paper31.pdf.

17. Biering-Sorensen E, Pedersen V, Clausen S. Epidemiology of spinal cord lesions in Denmark. Paraplegia. 1990;28:105-18.

18. Divanoglou A, Seiger A, Levi R. Acute management of traumatic spinal cord injury in a Greek and a Swedish region: a prospective, population-based study. Spinal Cord. 2010;48:477-82.

19. Knutsdottir S, Thorisdottir H, Sigvaldason K, Jonsson H Jr., Bjornsson A, Ingvarsson P. Epidemiology of traumatic spinal cord injuries in Iceland from 1975 to 2009. Spinal Cord. 2012;50: $123-6$.

20. Koskinen EA, Alen M, Vaarala EM, Rellman J, Kallinen M, Vainionpaa A. Centralized spinal cord injury care in Finland: unveiling the hidden incidence of traumatic injuries. Spinal Cord. 2014;52:779-84.

21. McCaughey EJ, Purcell M, McLean AN, Fraser MH, Bewick A, Borotkanics RJ, et al. Changing demographics of spinal cord injury over a 20-year period: a longitudinal population-based study in Scotland. Spinal Cord. 2016;54:270-6.

22. Chamberlain JD, Deriaz O, Hund-Georgiadis M, Meier S, ScheelSailer A, Schubert M, et al. Epidemiology and contemporary risk profile of traumatic spinal cord injury in Switzerland. Inj Epidemiol. 2015;2:28.

23. Lee BB, Cripps RA, Fitzharris M, Wing PC. The global map for traumatic spinal cord injury epidemiology: update 2011, global incidence rate. Spinal Cord. 2014;52:110-6. 
24. Sabre L, Pedai G, Rekand T, Asser T, Linnamagi U, Korv J. High incidence of traumatic spinal cord injury in Estonia. Spinal Cord. 2012;50:755-9.

25. Lenehan B, Street J, Kwon BK, Noonan V, Zhang H, Fisher CG, et al. The epidemiology of traumatic spinal cord injury in British Columbia, Canada. Spine (Phila Pa 1976). 2012;37:321-9.

26. Hagen EM, Rekand T, Gilhus NE, Gronning M. Traumatic spinal cord injuries--incidence, mechanisms and course. Tidsskr Nor Laege. 2012;132:831-7.

27. Singh A, Tetreault L, Kalsi-Ryan S, Nouri A, Fehlings MG. Global prevalence and incidence of traumatic spinal cord injury. Clin Epidemiol. 2014;6:309-31.

28. Oksuzyan A, Juel K, Vaupel JW, Christensen K. Men: good health and high mortality. Sex differences in health and aging. Aging Clin Exp Res. 2008;20:91-102.

29. Ferro S, Cecconi L, Bonavita J, Pagliacci MC, Biggeri A, Franceschini M. Incidence of traumatic spinal cord injury in Italy during 2013-2014: a population-based study. Spinal Cord. 2017;55:1103-7
30. Majdan M, Brazinova A, Mauritz W. Epidemiology of traumatic spinal cord injuries in Austria 2002-2012. Eur Spine J. 2016;25:62-73.

31. Sekhon LH, Fehlings MG. Epidemiology, demographics, and pathophysiology of acute spinal cord injury. Spine (Phila $\mathrm{Pa}$ 1976). 2001;26:S2-12.

32. Spiess MR, Muller RM, Rupp R, Schuld C, van Hedel HJ. Conversion in ASIA Impairment Scale during the first year after traumatic spinal cord injury. J Neurotrauma. 2009;26:2027-36.

33. deVivo M. Epidemiology of spinal cord injury. In: Lin VW, editor. Spinal cord medicine principles and practice. 2nd ed. New York, NY: Medos Medical Publishing; 2010. p. 78-84.

34. Sabre L, Remmer S, Adams A, Vali M, Rekand T, Asser T, et al. Impact of fatal cases on the epidemiology of traumatic spinal cord injury in Estonia. Eur J Neurol. 2015;22:768-72.

\section{Affiliations}

\section{A. Halvorsen ${ }^{1,2} \cdot$ A. L. Pettersen ${ }^{1} \cdot$ S. M. Nilsen ${ }^{1,3} \cdot K_{\text {K. Krizak Halle }}^{1} \cdot$ E. Elmenhorst Schaanning ${ }^{4} \cdot$ T. Rekand $\mathbb{C}^{5,6}$}

1 Department of Medical Quality Registries, St Olavs hospital, Trondheim University Hospital, Trondheim, Norway

2 Clinic of Physical Medicine and Rehabilitation, Department of Spinal Cord Injuries, St. Olavs Hospital, Trondheim University Hospital, Trondheim, Norway

3 Center for Health Care Improvement, St. Olavs Hospital, Trondheim University Hospital, Trondheim, Norway
4 Department of Spinal Cord Injury, Follow up (inpatient), Sunnaas Rehabilitation Hospital, Nesodden, Norway

5 Department of Neurology, Haukeland University Hospital, Bergen, Norway

6 Sahlgrenska Academy, Institute for Physiology and Neuroscience, University of Gothenburg, Gothenburg, Sweden 